\title{
Surgical palliation for an infant with hypoplastic left heart syndrome and congenital lobar emphysema: a case report.
}

Serena T. Pham, MD'; Raj Sahulee, DO*

${ }^{1}$ Division of Cardiothoracic Surgery, University of California, Davis, Sacramento, California.

${ }^{2}$ Division of Cardiology, Department of Pediatrics, New York University Grossman School of Medicine, New York.

*Corresponding Author: Raj Sahulee, Division of Cardiology, Department of Pediatrics, New York University Grossman School of Medicine, New York.

Received Date: February 19, 2021; Accepted Date: March 05, 2021; Published Date: March 09, 2021.

Citation: Serena T. Pham, R Sahulee. (2021) Surgical palliation for an infant with hypoplastic left heart syndrome and congenital lobar emphysema: a case report. Journal of Cardiology Research and Reports, 3(1): Doi: 10.31579/2692-9759/015

Copyright: () 2021, Raj Sahulee. This is an open-access article distributed under the terms of the Creative Commons Attribution License, which permits unrestricted use, distribution, and reproduction in any medium, provided the original author and source are credited.

\begin{abstract}
:
Hypoplastic left heart syndrome is a form of congenital heart disease that is associated with significant lifelong morbidity and mortality. Although rarely reported together, the prognosis for patients with hypoplastic left heart syndrome and congenital anomalies of the airway or lung, such as congenital diaphragmatic hernia, has been shown to be very poor. The outcomes for patients with hypoplastic left heart syndrome and congenital lobar emphysema specifically is currently unknown. Reported herein is the first case of a child with a rare combination of hypoplastic left heart syndrome and congenital lobar emphysema, and a discussion of his presentation, diagnosis, management and outcome to date.
\end{abstract}

Keywords: hypoplastic left heart syndrome; congenital lobar emphysema; congenital lung malformation

\section{Introduction:}

Hypoplastic left heart syndrome (HLHS) is a form of congenital heart disease with underdeveloped structures of, and reduced flow through, the left heart. Congenital lobar emphysema (CLE) is a congenital lung malformation (CLM) with air trapping and hyperinflation of one or more pulmonary lobes and mass effect to the adjacent tissues [1]. Congenital lobar emphysema with HLHS has not yet been described. We report a case of a child born with both CLE and HLHS who successfully underwent lobectomy and subsequent palliative cardiac surgery through superior cavopulmonary anastomosis.

\section{Case presentaion:}

A $2000 \mathrm{~g}$ male was born at 37 -week gestation via scheduled cesarean section due to intrauterine growth restriction and breech presentation to a 38-year-old gravida 4 para 1 with two prior miscarriages and one 38-week intrauterine fetal demise. Fetal echocardiography at 35-week gestation demonstrated severely hypoplastic left ventricle, mitral, and aortic valves. He had a spontaneous, vigorous cry at birth and Apgar scores were 8 and 8 at one and five minutes. Positive end-expiratory pressure was provided via Neopuff for initial saturation of $60 \%$, which later increased to $90 \%$. Initial chest radiograph showed left hemithorax opacification and mediastinal shift (Figure 1). Transthoracic echocardiography confirmed severely hypoplastic left ventricle and mitral valve, prolapsed tricuspid valve through a small ventricular septal defect with left ventricular outflow tract obstruction, and patent foramen ovale and ductus arteriosus. Prostaglandin E1 infusion at $0.05 \mathrm{mcg} / \mathrm{kg} / \mathrm{min}$ was started to keep ductus arteriosus patent, and milrinone at $0.5 \mathrm{mcg} / \mathrm{kg} / \mathrm{min}$ to decrease systemic vascular resistance. Chest computed tomography scan findings confirmed the presence of CLE (Figure 2). Rigid bronchoscopy at three days of age showed left upper lobe (LUL) bronchus obliteration. Patient was subsequently transferred from the neonatal intensive care unit to the congenital cardiovascular care unit for evaluation for cardiac surgery. 


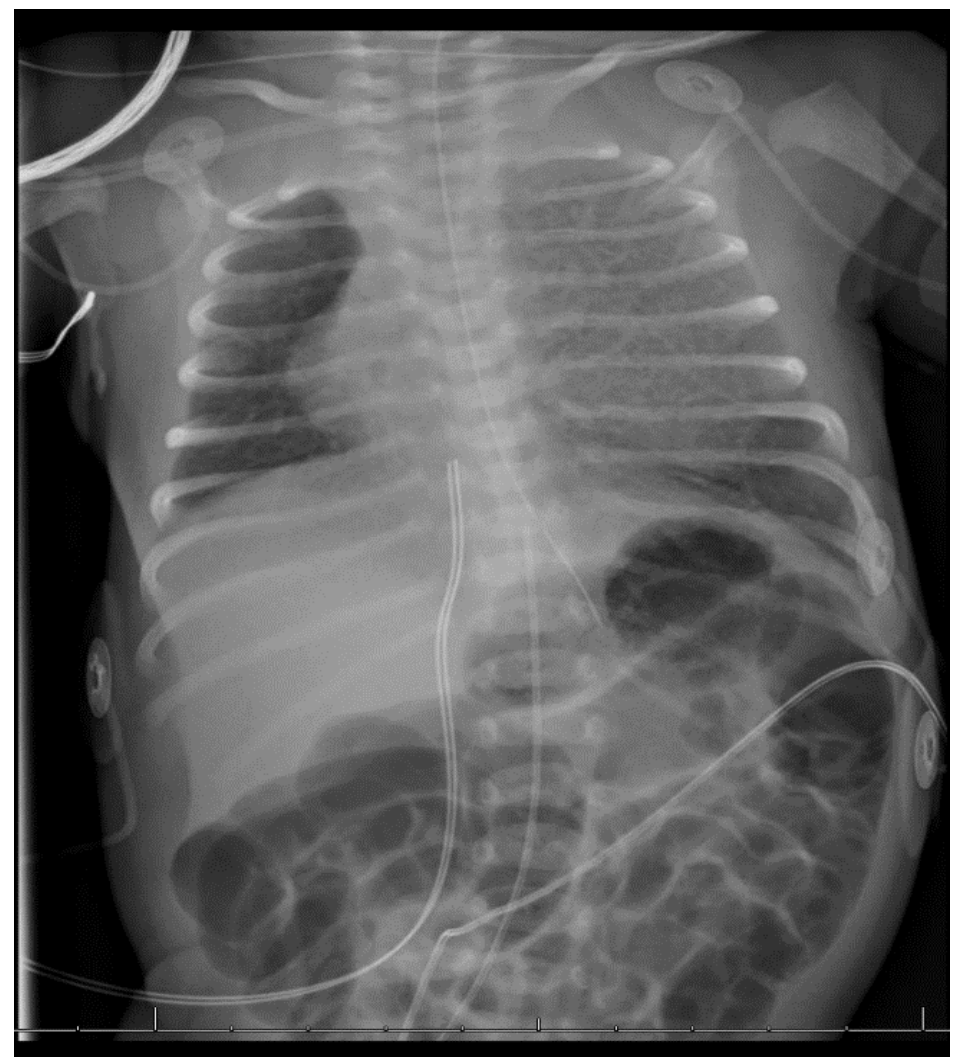

Figure 1: Preoperative chest radiograph. Mediastinal shift to the right with opacification in the majority of the left hemithorax.

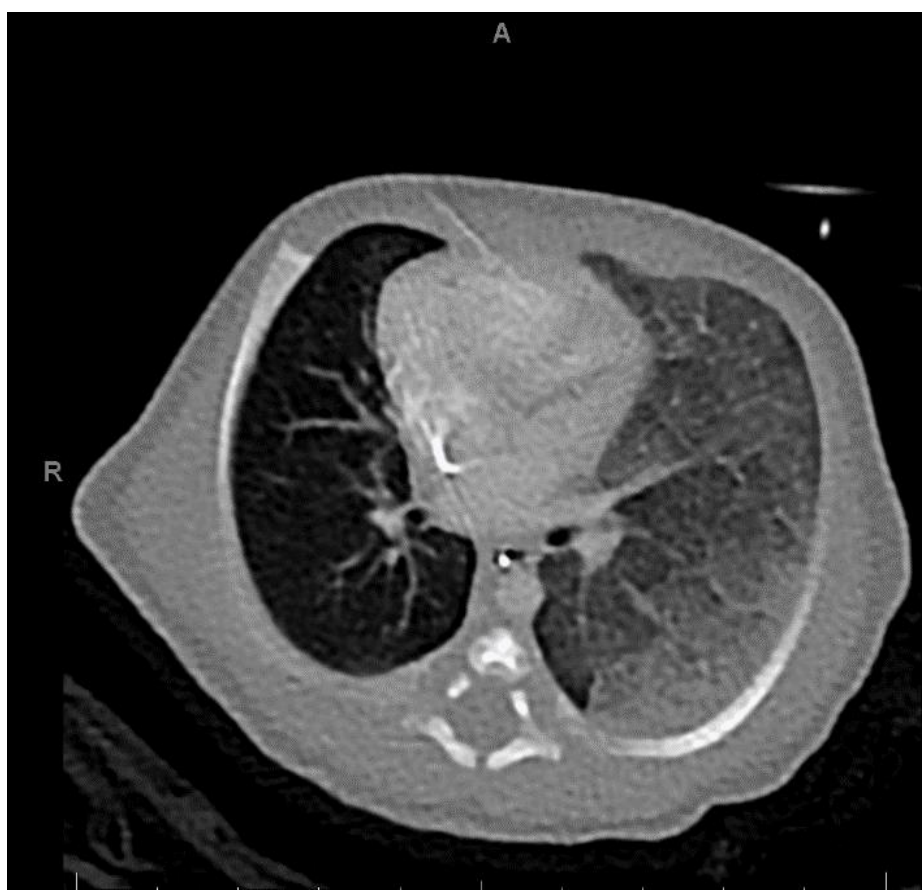

Figure 2: CT scan of the chest. Ground-glass attenuation and interlobular septal thickening of the overinflated left upper lobe.

While awaiting palliation, at six days of age, he required endotracheal intubation for worsening respiratory acidosis and LUL hyperinflation on chest radiograph. Fluid resuscitation and inotropes were initiated to improve systemic perfusion. After multidisciplinary discussion, he underwent an uncomplicated LUL resection the following day. Intraoperative findings included fusion of the anterior fissure, lingula, and the posterior aspect of the major fissure to the lower lobe with no lobar bronchus. Immediate postoperative chest radiograph revealed resolution of the hyperlucent LUL and decreasing atelectasis in the left lower lobe (Figure 3). The patient remained intubated postoperatively due to persistent respiratory acidosis and distress. 


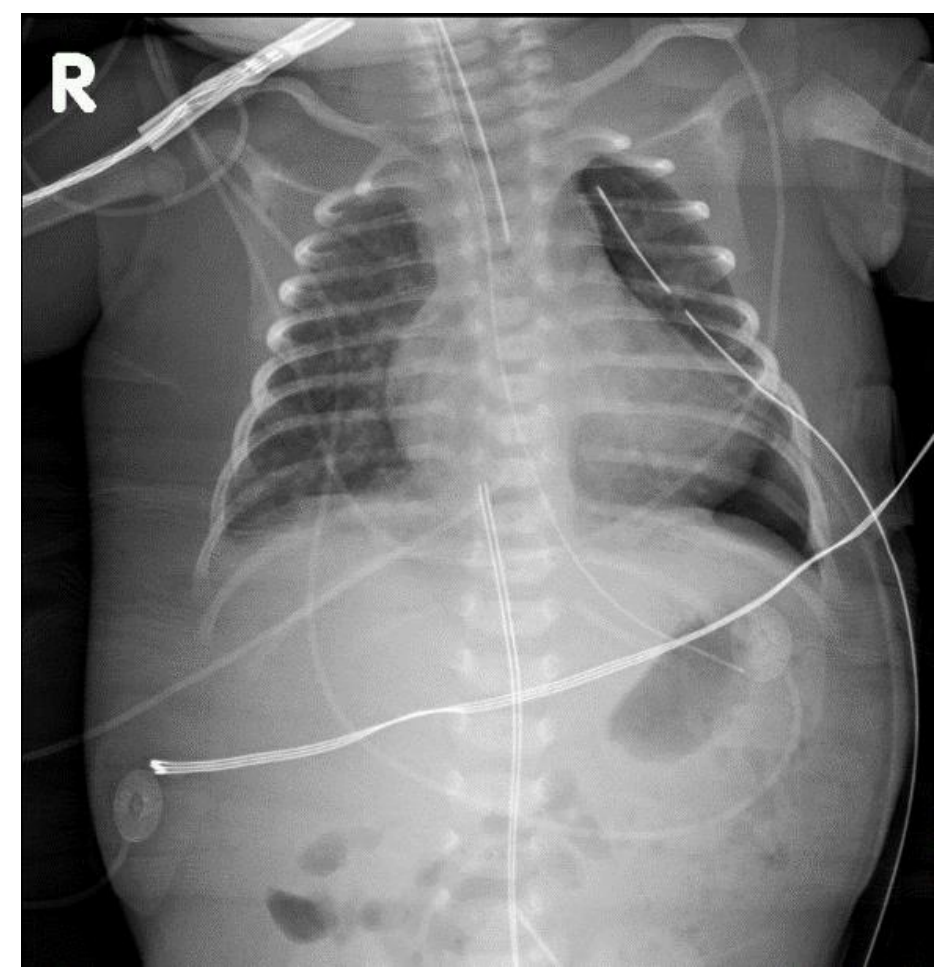

Figure 3: Post-lobectomy chest radiograph. Hyperlucency in left upper lung field is no longer visualized, and no pneumothorax.

At 14 days of age, he experienced worsening pulmonary overcirculation, and systemic hypoperfusion. He subsequently taken to the operating room and underwent bilateral pulmonary artery banding with the goal of controlling pulmonary circulation and improve systemic circulation prior to the Norwood procedure. He initially experienced marginal systemic perfusion due to hypovolemia and mildly diminished ventricular function for which he received fluid resuscitation, a blood transfusion, and lowdose epinephrine with gradual improvement in perfusion and lactate level. The patient remained intubated postoperatively due to persistent respiratory acidosis and distress, and required nicardipine for persistent hypertension.

At 30 days of age, he underwent bilateral pulmonary artery debanding and the Norwood procedure with Sano modification. Postoperative transesophageal echocardiography showed unobstructed aortopulmonary anastomosis and neo-aortic valve, mild aortic regurgitation, antegrade flow across the left ventricular outflow tract and native aortic valve, unrestrictive left-to-right interatrial flow after atrial septectomy, dilated right ventricle with normal systolic function, and flow throughout the patent Sano and proximal pulmonary artery branches. He was separated from bypass on milrinone and epinephrine. Enteral feeding and aspirin for Sano thromboprophylaxis were initiated on postoperative day (POD) 3 . He was extubated on SiPAP on POD 7, off all inotropes by POD 9, weaned to room air on POD 11, and discharged on POD 15 on oral and nasogastric feeding.

During the interstage period, he did not experience any difficulty breathing that required hospitalization, and his baseline saturations remained approximately $80 \%$. He grew consistently, on average $15.3 \mathrm{~g} /$ day, but remained < 1 st percentile in weight, and was routinely monitored by our institution's home monitoring program. Transthoracic echocardiography showed adequate ventricular contractility, patent atrial septal defect, and well-formed pulmonary artery branches. At five months old, diagnostic cardiac catheterization confirmed the aforementioned findings with calculated Qp:Qs of $0.5: 1$ and pulmonary vascular resistance index of 3.4 WU.m [2].
At seven months of age, he underwent the hemi-Fontan procedure. Postoperative transesophageal echocardiograph demonstrated adequate right ventricular systolic function and unobstructed cavopulmonary anastomosis. Patient was extubated on POD 0. His postoperative course was complicated by systemic hypertension for which he received intravenous nicardipine, which later was switched to oral amlodipine. It was also complicated by a urinary tract infection with frequent emesis for which he received intravenous antibiotics. Enteral feeds were started on POD 7 when his emesis resolved and he was discharged on POD 12 in stable condition.

In the 2 years since his discharge from his hemi-Fontan procedure, he has had three readmissions for viral respiratory infections, and a cardiac catheterization to occlude veno-venous collaterals. $\mathrm{He}$ has been maintaining adequate growth trajectory, and weaned off nasogastric feeding, but remains low weight for age (z-score -4.52). He also works with speech and physical therapy for gait training secondary to global hypotonia, pes planovalgus, and developmental delays. Fortunately, despite his underlying CLE, he has had no significant clinical respiratory sequelae after the lobectomy.

\section{Discussion:}

Hypoplastic left heart syndrome is a uncommon form of CHD with an incidence of 1.8 in 10,000 live births but accounts for $25 \%$ cardiac deaths in the first week of life [2]. Congenital lobar emphysema is a rare CLM with an incidence of 1 in 20,000-30,000 live births and male-to-female ratio of 3:1[1]. Associated congenital heart defects seen with CLE include tetralogy of Fallot with absence of pulmonic valve, total pulmonary venous return anomaly, patent ductus arteriosus, and atrial and ventricular septal defects [3]. We present the first report of a child with CLE and HLHS successfully managed through his superior cavo-pulmonary anastomosis.

Patients with CLE have respiratory insufficiency and abnormal pulmonary mechanics that theoretically make successful univentricular 
palliation challenging. Previous reports described mechanical ventilation at the time of, and following correction of congenital heart defects, can worsen CLE [4]. This is best exemplified by mortality rates of $40-100 \%$ seen in patients with HLHS and CLM, particularly congenital diaphragmatic hernia [5]. Some reports emphasized the importance of evaluating for CLE in setting of congenital heart disease to prevent prolonged respiratory distress and ventilation dependence in postoperative period, and have debated about management options for children with CLE and congenital heart disease - to address cardiac versus pulmonary defects first, or both simultaneously [4,6]. In this case, it was believed that the child's early presentation of severe respiratory distress would compromise his recovery from cardiac surgery. Hence, he underwent LUL resection and pulmonary artery banding prior to Norwood procedure. Fortunately, after the lobectomy, his pulmonary mechanics improved sufficiently to hypothesize that he would have an adequate reduction in pulmonary vascular resistance that he could eventually undergo successful superior cavo-pulmonary anastomosis.

We herein report the first case of an infant with HLHS and CLE, and successful outcome through his superior-cavopulmonary anastomosis and following two years. Since patient outcomes with HLHS and any form of CLM, including CLE, congenital cystic adenomatoid malformation, and pulmonary sequestration are unknown, further multi-center studies are needed to best describe the prevalence and outcomes for these unique and challenging patients.
Acknowledgement: All authors approve the final manuscript as submitted and agree to be accountable for all aspects of the work.

Disclosure: All authors declare no conflicts of interests and any proprietary or commercial interests in any products mentioned in this article.

\section{References:}

1. Demir O, Hangul M, and Kose M. (2019) Congenital lobar emphysema: diagnosis and treatment options. Int $\mathrm{J}$ Chron Obstruct Pulmon Dis.14:921-928

2. Gobergs R, Salputra E, and Lubaua I. (2016) Hypoplastic left heart syndrome: a review. Acta Med Litu.23(2):86-98

3. Nakata, T, Ikeda, T, Date, H, Doi, H, Baba, S, Hirata, T, Sakata R. (2014) Ventricular Septal Defect Complicated by Infantile Lobar Emphysema. Ann Thorac Cardiovasc Surg.20:901-903

4. Nakata T, Ikeda T, Date H, Doi H, Baba S, Hirata T, Sakata R. (2014) Ventricular Septal Defect Complicated by Infantile Lobar Emphysema. Ann Thorac Cardiovasc Surg.20:901-903

5. Balduf K, Kumar TKS, Boston U, Sathanandam S, Lee M, Jancelewicz T, Knott-Craig C. (2018) Improved Outcomes in Management of Hypoplastic Left Heart Syndrome Associated with Congenital Diaphragmatic Hernia: An Algorithm Approach. Semin Thoracic Surg.30:191-196

6. Gordon I and Dempsey JE. (1990) Infantile Lobar Emphysema in Association with Congenital Heart Disease. Clinical Radiology.41:48-52

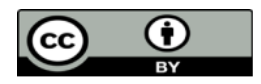

This work is licensed under Creative Commons Attribution 4.0 License

\section{To Submit Your Article Click Here: Submit Manuscript}

DOI: $10.31579 / 2692-9759 / 015$
Ready to submit your research? Choose Auctores and benefit from:

* fast, convenient online submission

* rigorous peer review by experienced research in your field

* rapid publication on acceptance

* authors retain copyrights

* unique DOI for all articles

* immediate, unrestricted online access

At Auctores, research is always in progress.

Learn more www.auctoresonline.org/journals/cardiology-research-andreports 